www.jmscr.igmpublication.org

Index Copernicus Value: 79.54

ISSN (e)-2347-176x ISSN (p) 2455-0450

crossrefDOI: https://dx.doi.org/10.18535/jmscr/v7i2.118

\title{
Serum Amylase Levels in Acute Organophosphorus Poisoning and It's Correlation with Clinical Severity
}

\author{
Authors \\ Dr Kamleshwar Mahto ${ }^{1}$, Dr Rajesh Manocha ${ }^{2}$, Dr Charanjeet Kaur ${ }^{3}$ \\ ${ }^{1}$ Post Graduate Student \\ ${ }^{2}$ MD (Medicine) FIACM, Professor \& Consultant, Department of Medicine \\ ${ }^{3}$ Professor \& HOD, Department of Biochemistery \\ Guru Gobind Singh Indastha University, New Delhi
}

\section{Introduction}

Organophosphorus (OP) compounds have been widely used for a few decades in agriculture for crop protection and pest control. India is a predominantly agrarian country with about 60$80 \%$ rural population. Pesticides are routinely used for advanced farming. Therefore, a pesticide is an easy access source for suicidal purpose particularly after trivial family squabbles. Poisoning is seldom included as a priority for health research in India, though every year, hundreds of people are losing their lives prematurely from pesticide poisoning. Vomiting soon after consumption of pesticide and with its smell easily detected even by a lay person poses no diagnostic difficulty. Thereby, quite often, the victim is brought to a health center within an hour of consumption of the pesticide - usually OrganoPhosphorus Compounds (OHPs). This is the "Golden Hour" for clinical intervention, before irreversible "ageing" of toxic compounds in blood occurs. Primary Health Centers in India are known for lack of drugs, doctors and application of evidence-based treatment.
Organophosphorus cause irreversible inhibition of acetylcholinesterase and create symptoms collectively referred to as cholinergic crisis. Acetylcholinesterase assays are not commonly done in Indian secondary or tertiary centers. A major drawback of acetylcholinesterase assay is that the interaction between organophosphorus, acetylcholinesterase and oximes continue if the sample is left at room temperature for even a few minutes. Blood samples must be diluted and cooled immediately $\left(-20^{\circ} \mathrm{C}\right)$ to stop the reaction. which makes interpretation is difficult ${ }^{[1-2]}$. Serum amylase measured in plasma and there is no effect of temperature and duration in the blood.

OP poisoning cause's cholinergic stimulation of pancreas and sphincter of oddi which may lead to elevated serum amylase level. There are various studies which shows hyperamylesia in OP poisoning. In a study conducted in Japan by Sumiya et al, an increase in plasma amylase levels above the normal range have been found in $50 \%$ of the patients who developed respiratory failure. The study has found a positive correlation with amylase levels with respiratory failure in organophosphorus poisoning ${ }^{[3]}$. Bhardwaj et al 
have found that serum amylase is elevated in $47 \%$ of patients with organophosphorus poisoning ${ }^{[4]}$. Lee et al reported 44 patients with hyperamylasia in a group of 121 patients with organophosphate intoxication $^{[5]}$.

In this study we are observing serum amylase level in OP poisoning and its correlation with clinical severity. If any correlation is present it can help in early recognition and timely intervention of toxicity from these compounds are of great importance to physician and patients.

\section{Material and Method}

A prospective case control study was conducted on 40 organophosphorus poisoning cases on the basis of clinical finding and history and 20 normal individuals of similar age and sex as control.

Sample Size:

1.

$$
\mathrm{n} \geq \frac{\left(Z_{\alpha}+Z_{\beta}\right)^{2}}{(E S)^{2}}
$$

Where $Z_{\alpha}$ is value of $Z$ at two sided alpha error of $5 \%$ and $Z_{\beta}$ is value of $Z$ at power of $80 \%$ and $E S$ is effect size.

2) For comparing mean of two groups

$\mathrm{N}>=2\left(\underline{\text { standard deviation })^{2}} *\left(\mathrm{Z}_{\alpha}+\mathrm{Z}_{\beta}\right)^{2}\right.$ ${\text { (mean difference })^{2}}^{2}$

Where $Z_{\alpha}$ is value of $Z$ at two sided alpha error of $5 \%$ and $Z_{\beta}$ is value of $Z$ at power of $80 \%$ and mean difference is difference in mean values of two groups.

\section{Inclusion criteria}

Patients more than 12 year of age diagnosed as OP poisoning were the study subjects.

\section{Exclusion criteria}

1. Patients with OP poisoning and mixed with any other poison.

2. Patients who have consumed poison along with alcohol.

3. Patients who are chronic alcoholics.

4. Patients with history suggestive of gall stone disease, parotid gland disease, lipid disorders, hyperparathyroidism, renal or hepatic disease.

5. History of intake of drugs likely to produce pancreatitis -Eg: Azathioprine, Sulfonamide Mercaptopurine, Tetracycline, Thiazides, Valproic acid.

\section{Methods of Collection of Data}

Informed consent was taken from respective patients or legal guardian of the patient before recruitment for the study. Information was collected on a proforma from each patient.

Qualifying patients underwent detailed history, clinical examination and laboratory investigation. A thorough clinical examination was done and patients were categorized according to Brent and Wallace grading system of severity of OP poisoning $^{(6)}$.

\begin{tabular}{|c|c|c|c|c|c|}
\hline Grades & $\mathrm{CNS}$ & secretions & fasciculations & hypotenion & \\
\hline 0 & Awake, alert & - & - & - & Only history \\
\hline 1 & Awake, alert & + & + & - & \\
\hline 2 & drowsy & ++ & ++ & $+(\operatorname{sbp}<90)$ & \\
\hline 3 & Drowsy, comatose & +++ & +++ & ++ & Inc. fio2 \\
\hline 4 & comatose & +++ & +++ & ++ & $\begin{array}{l}\text { Pao } 2<60 \text { on fio } 2>40 \text {, } \\
\text { mechanical ventilation. }\end{array}$ \\
\hline
\end{tabular}

After a categorization blood sample were taken on $1^{\text {st }}$ day, $2^{\text {nd }}$ day and $4^{\text {th }}$ day for laboratory analysis. Serum amylase was measured on a fully
Automated clinical chemistry analyzer on ADVIA 2400 using commercially available kit. 
Observation and Result

Graph 1 Type of OP ingested by cases

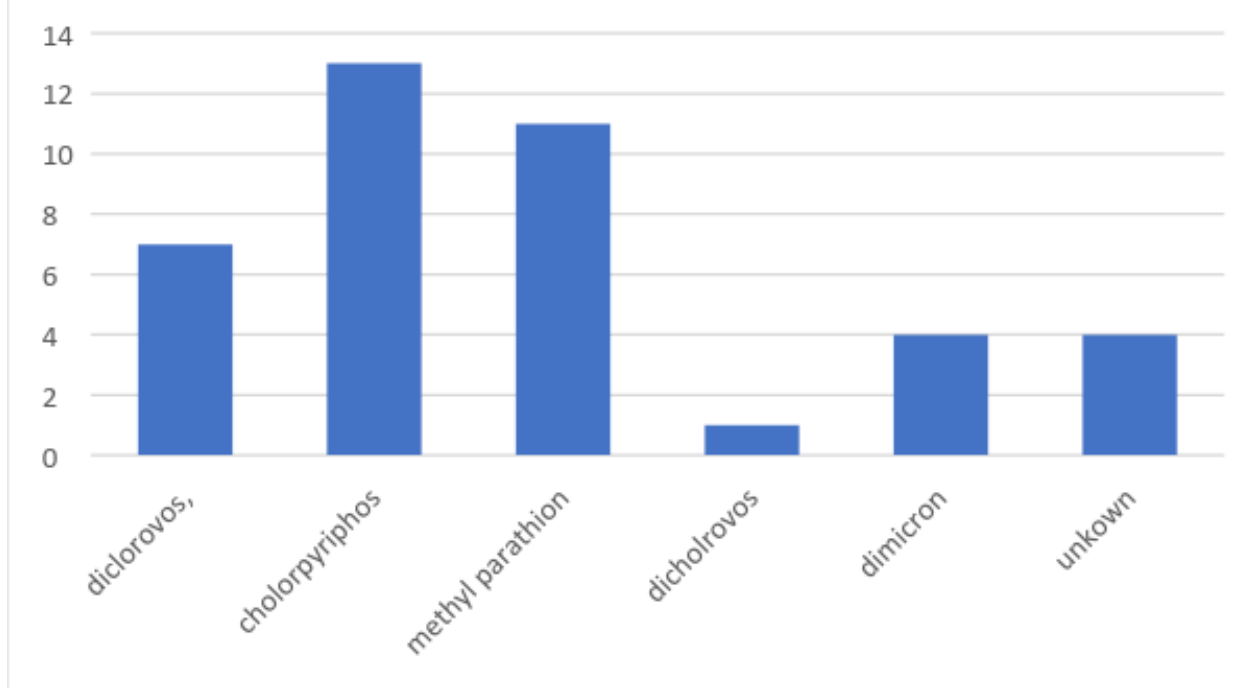

Chart-1 Mean serum amylase level between cases and controls

\begin{tabular}{|l|c|c|c|}
\hline & Case & Control & P value \\
\hline Sample size & 40 & 20 & \multirow{2}{*}{0.0001} \\
\cline { 1 - 3 } Serum amylase $1^{\text {st }}$ day & & & \\
\hline Mean \pm SD & $132.15 \pm 100.19$ & $51.35 \pm 19.57$ & \multirow{2}{*}{0.0003} \\
\hline Serum Amylase 2nd day & & & \multirow{2}{*}{0.0005} \\
\cline { 1 - 3 } Mean \pm SD & $125.22 \pm 99.97$ & $51.35 \pm 19.57$ & \\
\cline { 1 - 3 } Serum Amylase 4th day & & $51.35 \pm 19.57$ & \\
\cline { 1 - 3 } Mean \pm SD & $108.12 \pm 79.34$ & & \\
\cline { 1 - 3 }
\end{tabular}

Graph-2 Serum amylase trends on different days in cases.

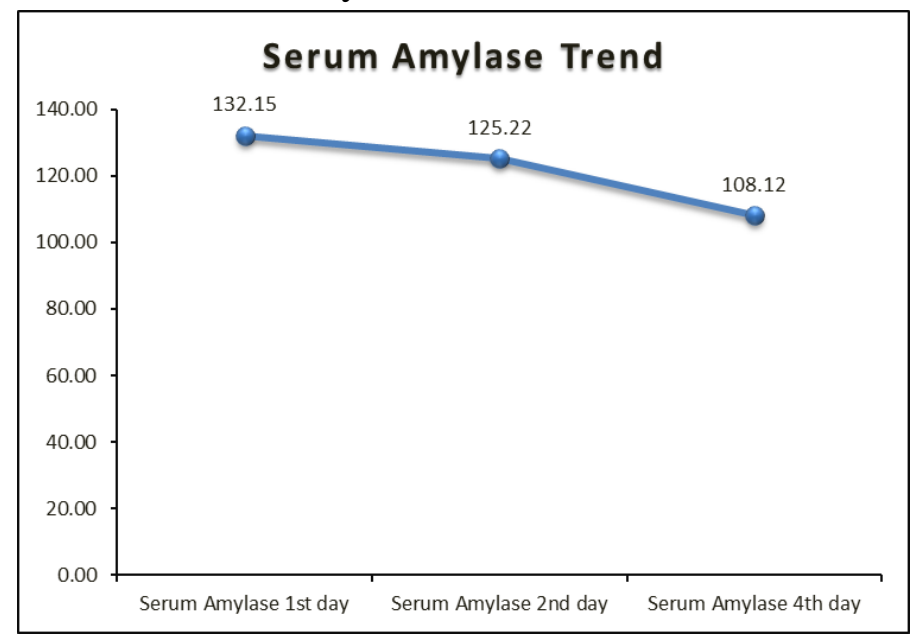


Chart-2 Significance of serum amylase level and severity

grade Day1

\begin{tabular}{|c|c|c|c|c|c|}
\hline & & & & $95 \% \mathrm{C}$ & Ids ratio \\
\hline & S.E. & $P$ value & Odds ratio & Lower & Upper \\
\hline Serum Amylase 1st day & .007 & .002 & 1.024 & 1.009 & 1.039 \\
\hline grade Day2 & & & & & \\
\hline & & & & $95 \% \mathrm{C}$. & Ids ratio \\
\hline & S.E. & $P$ value & Odds ratio & Lower & Upper \\
\hline Serum Amylase day 2 & .007 & .002 & 1.021 & 1.008 & 1.035 \\
\hline grade Day4 & & & & & \\
\hline & & & & $95 \% \mathrm{C}$. & Ids ratio \\
\hline & S.E. & $\mathrm{P}$ value & Odds ratio & Lower & Upper \\
\hline Serum Amylase day 4 & .009 & .010 & 1.023 & 1.005 & 1.041 \\
\hline
\end{tabular}

Chart-3 Correlation between serum amylase and course in hospital.

\begin{tabular}{|l|c|c|c|}
\hline & Died & Discharged & P value \\
\hline Serum Amylase & & & \multirow{2}{*}{0.019} \\
\cline { 1 - 3 } Sample size & 3 & 37 & \\
\cline { 1 - 3 } Mean \pm Stdev & $318.67 \pm 160$ & $117.03 \pm 79.48$ & \\
\hline Median & 298 & 80 & \\
\hline
\end{tabular}

\section{Discussion}

\section{Sex and Age Distribution}

In our study we have taken 40 cases out of which 22 were males and 18 were females. We have also included 20 normal controls out of which 11 are males and 9 are females both groups are comparable in sex distribution with male to female ratio 1.1:1. Previous studies does not have any control group which is included in our study.

In our study most of the cases and controls are in between age 21-30 yr $57.50 \%$ and $60 \%$ respectively. Cases and control below 20yr are $17 \%$ and $25 \%$ respectively. It shows both groups are comparable and shows no significant difference. This is the most critical period, when one is likely to face various problems that may lead to psychological stress, so a person may take drastic steps to end his life, consuming available poisons.

\section{Type of OP Consumption}

In our study most of the patients had taken termite killer insecticides which contains diclorovos, cholorpyriphos and methyl parathion. 13 cases used chloropyriphos, followed by methyl parathion in 11 cases, 7 of them used dicholrovos, dimicron was ingested by 4,1 of them used diazinon and 4 of them didn't not know what they had taken.

\section{Serum Amylase between Cases and Control}

All blood parameters are in normal range in both groups except serum amylase level which is raised in most of the OP poisoning cases. Median value of serum amylase in control is $(51.35 \pm 19.57)$ but in cases amylase level is raised on day $1(132 \pm 100.19)$ and on day 2(125.22 \pm 99.91$)$ and on day 4(108 \pm 79.34$)$ with P-value of less than 0.05 shows significant increase of serum amylase in cases.

\section{Serum Amylase in Cases}

Patients are diagnosed solely based on history and clinical examination. Patients were treated with standard treatment. Serum amylase level is studied on day of presentation on second day and on fourth day. Patients clinical severity were classified according to Brent and Wallace grading system which includes parameters like secretion, fasciculation, hypotension, CNS (awake, drowsy, comatose) and $\mathrm{PaO} 2$ level and patients are classified from grade 0 to 4 on day 1 , day 2 and day 4. 
Mean serum amylase level on day 1 is 132.15 and out of 40 cases most of them $45 \%$ were in grade- 3 and then in grade- $130 \%$ and $17.50 \%$ were in 0 grade and 5\% were in grade 2 and $2.5 \%$ in grade 4. Patients who are in grade 4 were comatose and they are in respiratory distress their $\mathrm{PaO} 2$ level below $60 \mathrm{~mm}$ of $\mathrm{Hg}$ and their serum amylase was above 300 . Other study W C Lee et $\mathrm{al}^{(5)}$ carried out a retrospective study of medical records of 121 patients. It was observed that 44 patients (36\%) had hyperamylasemia (Amylase>360 U/L). Ahmed Arshia et $\mathrm{al}^{(7)}$ conducted a descriptive study all patients of both sexes and ages above 15 years admitted with a positive history of organophosphate poisoning (OP) were included in the study. Among 90 patients, hyperamylasemia was found in $28(31 \%)$ patients. S Singh et al carried out a prospective study to find the incidence of hyperamylasemia and acute pancreatitis in patients with OP poisoning. Of the 79 patients studied, serum Amylase was found to be elevated (> 200 S.U) in 37 patients (46.95\%), among them in three patients it was 800 S.U.

Patient's serum amylase level gradually decreased by day 4 mean serum amylase was 108.12 and most of the patients $72 \%$ were in grade 0 of severity grading. 2 patients whose serum amylase were more than 250 and 1 patient whose serum amylase above 150 developed respiratory failure and required mechanical ventilation died in subsequent days. Mean serum amylase in all 3 patients is 318.67. In a study conducted in Japan by Sumiya et $\mathrm{al}^{(3)}$, an increase in plasma amylase levels above the normal range have been found in $50 \%$ of the patients who developed respiratory failure. Lin CL et $\mathrm{al}^{(8)}$, found that mean amylase levels were elevated in patients with respiratory support and serum amylase levels predicted ventilator support in OP poisoning .In the study conducted by Rohit et al ${ }^{(9)}$ among the 120 patients in the study, death was reported in $13(10.83 \%)$ patients and $107(89.16 \%)$ patients survived after mechanical ventilation.

Significance of serum amylase in predicting clinical severity is measured by using univariate logistic regression which shows $\mathrm{P}$ value of 0.002 on day1, 0.002 on day 2 and on day $4 \mathrm{P}$-value is 0.010 all values are less than 0.05 which shows statistical significance of serum amylase in predicting severity of OP poisoning.

\section{Conclusion}

- OP poisoning is most common in the age group between 21-30 yr.

- Serum amylase level is increased in patients with acute OP poisoning than in normal individuals.

- Serum amylase levels considered as a marker of organophosphorus intoxication, since it enables the early recognition of severity and also helps to identify those at risk of developing the complications of Organophosphorus poisoning.

\section{References}

1. Worek F, Mast U, Kiderlen D, Diepold C, Eyer P. Improved determination of acetylcholinesterase activity in human whole blood. Clinca Chimca Acta1999;288:73-90.

2. Reiner E, Buntic A, Trdak M, Simeon V. Effect of temperature on the activity of human blood cholinesterases. Arch Toxicol 1974;32:347-350.

3. Sumiya MN, Tanaka M, Iwai M, Konda T, Takahashi S, Sato $\mathrm{S}$ et al. Elevated serum amylase is related todevelopment of respiratory failure in organophosphate poisoning. Hum Exp Toxicol 1996;15:250-253.

4. Bhardwaj SSU, Verma SK, Bhalla A, Gill K. Hyperamylasemia and acute pancreatitis following anticholinesterase poisoning. Hum Exp Toxicol 2007;26:467-471.

5. Lee WC, Yang CC,Deng JF, Wu ML,Ger $\mathrm{J}$, Lin HC. The Clinical Significance of Hyperamylasemia in Organophosphate Poisoning. J Toxicol Clin Toxicol 1998;36:673-681. 
6. Brent J., Wallace K., Burkhart K,Phillips SD,Donovan J. Organophosphorus and carbamate insecticides, Methanol poisoning. Critical care Toxicology. Diagnosis and management of the critically poisoned patient. Philadelphia: Elsevier Mosby;2005:937-947.

7. Ahmed A, Begum I, Aquil N, Atif S, Hussain T, Vohra EA . Hyperamylasemia and acute pancreatitis following organophosphate poisoning. Pak J Med Sci 2009;25:957-961.

8. Lin CL, Yang CT, Pan KY, Huang CC. Most common intoxication in nephrology ward organophosphate poisoning. Ren Fail 2004;26:349- 354.

9. Rohit NS, Amar SW. Study of serum amylase levels in organophosphate poisoning. IJBAR 2017;8:450-454. 